\title{
"Una reunión de niños" Construcciones de conocimiento infantil sobre la política en un movimiento social
}

\section{(4) Paula Nurit Shabel \\ Universidad de Buenos Aires, Ciudad A. de Buenos Aires, Argentina CONICET, Ciudad A. de Buenos Aires, Argentina \\ Correo electrónico: paulashabel@gmail.com}

Recibido

Diciembre de 2017

Aceptado

Julio de 2018

doi: $10.34096 /$ cas.i49.4022

\section{Resumen}

Las reconfiguraciones políticas de las últimas décadas en Argentina produjeron nuevas estrategias de lucha y organización popular, que implicaron la movilización de las familias enteras al piquete, a la cooperativa de vivienda o a la marcha en la plaza. A partir de este proceso, miles de niños y niñas comenzaron a participar cotidianamente de prácticas políticas sobre las que construyen conocimiento. Sobre la base de un trabajo etnográfico realizado en una vivienda colectiva de un movimiento social de la Ciudad de Buenos Aires, indagaremos aquello que los niños y niñas conocen de la política, mientras producen sus propias prácticas de acción colectiva, abriendo una disputa de poder intergeneracional sobre el espacio. Utilizaremos también entrevistas clínico-críticas para reconstruir sus nociones, en tanto asumimos que estos sujetos no simplifican lo que piensan los adultos sobre las prácticas, sino que elaboran sus propios sentidos, siempre en relación con sus contextos sociales y materiales.

\section{“A Children's meeting". Constructions of children's knowledge about politics in a social movement}

\begin{abstract}
The political changes taken place in the last decades in Argentina brought about new strategies in the organization and struggles of the popular sectors, which entailed the mobilization of entire families to a picket, to housing cooperatives or to the demonstration to the plaza. Since then, thousands of children began to participate daily in political practices upon which they build knowledge. Drawing on ethnographic work developed in collective housing of a social movement in the city of Buenos Aires, I examine what children understand by politics, while they produce their own collective actions, opening up an intergenerational power dispute over space. Clinical-critical interviews were also be used to reconstruct their notions, as I assume these subjects do not simplify what adults think, but they elaborate their own meanings, always related to their social and material contexts.
\end{abstract}

\section{Palabras clave}

Niños y niñas; Construcción de conocimiento; Política; Movimiento social; Espacio

\section{Key words}

Children; Construction of knowledge; Politics; Social movement; Space 


\section{"Uma reunião de crianças". Construções do conhecimento infantil sobre a política em um movimento social}

\section{Resumo}

Palavras-chave

Crianças; Construção do conhecimento; Política; Movimento social; Espaço
1. Los números entre paréntesis refieren en todos los casos a las edades de las personas, cuyos nombres han sido modificados para preservar sus identidades.
As reconfigurações políticas das últimas décadas na Argentina produziram novas estratégias de luta e de organização popular, que envolveram a mobilização de famílias inteiras para os "piquetes", as cooperativas de habitação ou a marcha nas praças. A partir desses processos, milhares de crianças começaram a participar diariamente de práticas políticas através das quais constroem conhecimento. A partir de um trabalho etnográfico em um plano de habitação coletivo de um movimento social da Cidade de Buenos Aires, pesquisamos o que as crianças entendem por política, enquanto produzem suas próprias práticas de ação coletiva, abrindo uma disputa de poder inter-geracional sobre o espaço. Também utilizamos entrevistas clínico-críticas para reconstruir suas noções, enquanto assumimos que esses sujeitos não simplificam o que os adultos pensam sobre as práticas, mas que elaboram seus próprios sentidos, sempre em relação aos seus contextos sociais e materiais.

\section{Introducción}

Llego a la puerta de la casa del Movimiento, en pleno centro porteño, y entro porque está abierta la puerta, sin llave. A veces pasa, sobre todo en horarios de la tarde donde todas las familias que allí viven [más de treinta] entran y salen del trabajo, la escuela, la plaza [...]. Saludo a un par de mujeres acostumbradas a verme, tanto por el trabajo de campo como por mi acompañamiento político al Movimiento. Escucho las voces de los chicos que andan en los pasillos jugando a alguna cosa, como siempre. En el primer piso me encuentro con Natalia (13), ${ }^{1}$ Florencia (9), Pablo (8) y Ema (9) sentados en el piso, alrededor de una cartulina en la que estaban escribiendo algo hasta que me vieron y la taparon. Los saludo y les pregunto qué tienen ahí y me dicen que algo de la escuelita y se ríen y discuten si me muestran o no [...]. Finalmente me muestran el contenido de la cartulina [Figura 1] y me explican que están cansados de que no los dejen jugar en ningún lado de la Casa y de que les saquen la pelota cuando lo están haciendo [...].

En la cartulina, Natalia (13) hace los renglones en lápiz y escribe con un marcador negro grueso y algunos de colores que fueron trayendo entre todos. Van decidiendo qué poner, lo charlan y Natalia (13) lo escribe. Están sentados en el piso y miran cautelosos cuando pasa un adulto por si les dice algo, pero nadie parece estar controlando ni atendiendo a lo que hacen o dejan de hacer los chicos [...].

Mientras escriben, dicen que antes tenían el patio para jugar y que ahora no porque hay autos, un estacionamiento que se paga y que los grandes tienen miedo de que los chicos les hagan algo a los autos cuando juegan, que "prefieren cuidar los autos que dejarnos jugar". Repiten varias veces "queremos un espacio", "no tenemos lugar para jugar” y continúan con la producción del cartel. (Movimiento, Buenos Aires, agosto 2016)

Este fragmento de registro parece responder por sí mismo a la pregunta por las construcciones de conocimiento sobre la política que realizan los niños y niñas que viven en la casa colectiva del Movimiento, ubicada en un céntrico barrio de la ciudad de Buenos Aires. Sin embargo, decidimos renunciar a la supuesta autoevidencia del texto para 


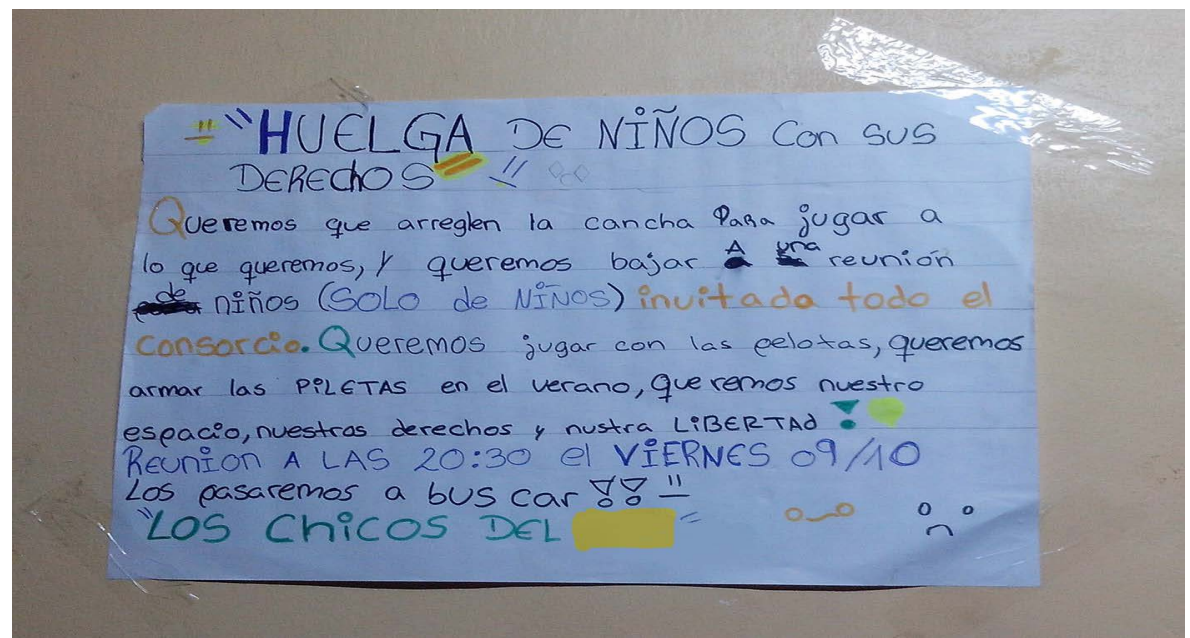

indagar cautelosamente en los marcos de significación, en tanto estructuras cognitivas (Castorina, 2012), que ellos y ellas van erigiendo en su particular contexto simbólico y material en torno a aquellas "figuras de lo político" que la antropología ha recortado "de un fondo (de prácticas sociales) sobre el que las distingue" (Cañedo Rodríguez y Espinosa, 2011, p. 11). El objetivo del presente trabajo es, entonces, indagar aquello que conocen como política los niños y niñas del Movimiento, mientras producen sus propias prácticas de acción colectiva, con lo cual abren una disputa de poder intergeneracional sobre el espacio.

Este Movimiento nació en el año 2001, en contexto del estallido social, producto de la crisis económica de ese año, tras una década de deterioro bajo el régimen neoliberal. En el seno de este proceso se reconfiguró el campo popular, en el que interactuaron viejas y nuevas formas de lucha, lo que dio lugar a novedosas organizaciones (Bonnet, 2008), como es el caso del movimiento piquetero ${ }^{2}$ donde realizamos nuestro campo. Este se convirtió luego en un movimiento social y en una cooperativa de vivienda. Con una estructura nacional, el Movimiento en Capital Federal "se caracteriza por la ocupación colectiva de casas y edificios públicos y privados, con el objetivo de la obtención de lugares de vivienda para las familias" (Poli, 2007, p. 65), como muchas otras organizaciones en los contextos de pobreza urbana (Girola y Thomasz, 2013).

Fue en una de estas casas donde desarrollamos el presente trabajo, particularmente, en una vivienda que fue tomada por el Movimiento hace más de quince años y que, desde entonces, pertenece a la categoría de Hospedaje Transitorio del Movimiento, ${ }^{3}$ en tanto sostiene un precario (y siempre en peligro) acuerdo con el Gobierno de la Ciudad y el dueño del inmueble que evita el desalojo. Muchos de los niños y niñas que hacen a esta investigación nacieron en esta vivienda y crecieron juntos, van a las escuelas del barrio, al espacio de apoyo escolar de la esquina, etc. Si bien hay niños y niñas de todas las edades, nos concentraremos aquí en el grupo de unos 20, que tienen entre 6 y 14 años, en tanto fue el protagonista del reclamo por el espacio de juego.

Para cerrar esta introducción, me interesa evocar ciertos puntos en el recorrido del proceso de investigación en la casa. Lo cierto es que, antes de presenciar esta situación, había fracasado reiteradas veces en mis intentos por reconocer lo político en las vidas de estos chicos y chicas. Indagué sobre las nociones que relacionan con la palabra "política" y realicé entrevistas sobre los diversos procesos electorales, fui a las marchas del Movimiento con ellos, a algún acto, en búsqueda de aquello que estos niños y niñas significaban de lo que estaba pasando. En general, nada de esto parecía importarles demasiado. El cartel proclamando una "huelga de niños" una tarde cualquiera me obligó a redireccionar la mirada y a repensar las relaciones entre las estructuras de poder y las
Figura I. Cartel de convocatoria a una reunión elaborado por los niños y niñas de la casa tomada (el nombre del Movimiento fue borrado del cartel para esta presentación).

2. Los movimientos piqueteros nacieron a fines de la década de 1990 como respuesta a los despidos masivos y a la falta de empleo generada por las privatizaciones de empresas como política de Estado (Bonnet, 2008).

3. Un hospedaje transitorio es, dentro del Movimiento, una casa tomada que, a partir de un proceso de resistencia de las familias y la presión política de las manifestaciones, logró un convenio con el Estado local y el dueño. En él se establece que las familias de la casa se comprometen a pagarle al Estado un accesible alquiler colectivo, que este completa con el dinero restante, para otorgarle al propietario del inmueble la totalidad del pago del alquiler, que es mayor a lo que el Movimiento puede pagar, aunque no llega a ser lo que el dueño podría cobrar por esa propiedad en caso de alquilarla a un privado. 
prácticas sociales y culturales cotidianas para el caso particular de estos sujetos. Desde esta mirada coincidimos con María Inés Fernández Álvarez cuando afirma que "Lo político no está dado, sino que es el producto de la acción humana, es aquello que los hombres y mujeres hace(mos) existir como tal a través de relaciones de fuerza" (2015, p. 28) y ponemos el foco en las prácticas y experiencias de la política, advirtiendo que las estudiamos para trascenderlas y conceptualizarlas.

\section{La política no es juego de niñxs}

La apuesta del trabajo que aquí presentamos es poner en diálogo la dimensión de las prácticas cotidianas de la antropología política y las relaciones de poder (Manzano, Fernández Álvarez, Triguboff y Gregoric, 2008; Grimberg, 2009) con los estudios de infancia, asumiendo su complejidad, en tanto niños y niñas han sido históricamente considerados sujetos no-políticos (Carli, 2012), así como también no-productivos, alegando su incapacidad y una pureza etaria proclive a corroerse en dichas esferas de la vida social (Gentile, 2015; Szulc y Enriz, 2016). Los chicos y chicas han sido por ello visibles únicamente allí donde se esperaba que estuvieran: en la escuela, en la familia, incluso en la iglesia, mientras que aquí proponemos considerar que "las identidades de los niños son también de clase, raza, género, etc., así como las identidades de género, clase y raza están atravesadas por las relaciones niñez-adultez" (Holloway y Valentine, 2000, p. 5, traducción propia). El presente trabajo se propone poner en juego estas relaciones en el campo particular del Movimiento y descartar todo tipo de evaluaciones sobre las formas de vivir la infancia o de hacer política de la organización.

En pos de tal objetivo, recuperamos una reciente línea de investigaciones locales sobre las infancias pobres que viene realizando interesantes publicaciones sobre los efectos que la dictadura cívico-militar y la imposición del régimen neoliberal tuvieron sobre este grupo, cuya vida se vio pauperizada y sometida a las peores desigualdades (Carli, 2009). Así, hoy contamos con esclarecedores análisis sobre chicos y chicas en situación de calle, en hogares, en villas, en barrios pobres del conurbano, que trabajan, que mendigan, etcétera (Szulc, 2006; Hernández, Chaves y Cingolani, 2012; Santillán, 2012; Villalta, 2013; Gentile, 2015). Con la presente investigación doctoral en curso pretendemos realizar un incipiente aporte, para dar visibilidad a otro aspecto de estas infancias, ligado a las prácticas políticas cotidianas que desarrollan los movimientos, como nuevos escenarios en los que se desenvuelve la vida y, por lo tanto, se crían hijos, se crece y se conoce (Padawer, Scarfó, Rubinstein y Visintin, 2008; Santillán, 2009; Scarfó, 2010; Gentile, 2011).

El avance del capital sobre el trabajo que se produjo desde fines de los años setenta en la Argentina ( $y$ en toda América Latina) encontró en el campo popular una asombrosa creatividad para generar nuevas estrategias de resistencia e incluso ofensiva contra el despojo y la precarización. Se produjo, en este sentido, una reconfiguración del campo político con nuevas experiencias de lucha y organización que implicaron la movilización de las familias enteras al piquete, la cooperativa de vivienda o la marcha en la plaza (Bonnet, 2008). Así se visibilizaron diversos colectivos con reclamos particulares (de género, étnicos, ambientales, etc.) y se territorializaron los espacios de lucha, con una fuerte irrupción de mujeres y niños y niñas en escena (Shabel, 2017), lo que da cuenta de "cómo en los contextos contemporáneos de desigualdad y transformación de las formas de intervención social, la crianza y educación de los niños [...] es una cuestión en creciente politización" (Santillán, 2009, p. 70). Ya no solo la producción, sino la reproducción de la vida, pasaron a formar parte de la práctica política cotidiana, y es allí donde cabe la pregunta por los sentidos que niños y niñas le otorgan a esa dimensión de sus propias vidas. 


\section{Construcciones de conocimiento infantil al sur del sur}

Estas reconfiguraciones sociales en general - y generacionales en particular-, lejos de los escandalosos discursos que proclamaron el fin de la infancia pura e inocente (blanca y burguesa), nos obligan a visibilizar una diversidad de experiencias de infancias y a "reconocer las pérdidas, al tiempo y a la infancia que pasaron, y a apostar y hacer en el presente para la construcción de otras alternativas" de esta etapa de la vida (Rabello de Castro, 2002, p. 47, traducción propia). Desde una perspectiva poscolonial, que critica tanto el discurso de los países como de los niños en desarrollo, estos supuestos niños sin niñez del tercer mundo, con experiencias de trabajo, participación política o, incluso, en situación de calle, no son ni más ni menos niños o niñas que aquellos que cumplen con los parámetros hegemónicos de normalidad, así como nadie es más o menos adulto por su condición de clase o étnica (Liebel, 2016). La infancia no es conceptualizada en este paradigma como una fase preparatoria para el futuro, sino como una categoría estructural, constitutiva de cualquier sociedad (Qvortrup, 2010), que se ve afectada en formas particulares ante las transformaciones sociohistóricas.

Siguiendo la misma línea argumental, crítica del sujeto trascendental kantiano masculino, adulto y burgués, asumimos que los niños y niñas no son sujetos incompletos (ni los adultos completos) que aún-no pueden, ni saben, ni conocen, sino sujetos plenos en sus acciones y reflexiones en y con el mundo. En este planteo, los procesos de construcción de conocimiento infantil se diferencian de una "prerrogativa asumida en una dirección unívoca en la transmisión intergeneracional, en que los más viejos son los que deben transmitir conocimiento a los más nuevos" (Rabello de Castro, 2008, p. 6), en tanto los niños y niñas no solo copian los saberes adultos o conocen solo aquello que los adultos habilitan, sino que realizan sus propias elaboraciones individuales en relación con el objeto particular de conocimiento (y su historia), con sus saberes previos y con el contexto de producción de los nuevos saberes (García Palacios y Castorina, 2010).

Con el objetivo de indagar las relaciones entre los procesos de conceptualización individual y las prácticas y discursos sociales de las que los niños y niñas participan, nos apoyamos en una reciente línea de la antropología que desarrolla un enriquecedor diálogo con la psicología genética ${ }^{4}$ (Toren, 2012; García Palacios, 2012). Estas autoras afirman que los significados que les otorgamos a las cosas no están nunca dados por completo, sino que contienen siempre un elemento emergente que aporta cada sujeto que lo aprende o incorpora. Por eso, para algunas nociones del conocimiento, los adultos pueden "saber más", pero no "saber mejor" que los chicos y chicas sobre algo (Toren, 2012); al menos, no saber mejor en abstracto, sino siempre en un marco de prácticas y discursos sociales que delimitan nociones de mayor o menor hegemonía. Si bien damos cuenta de la asimetría generacional existente a la hora de negociar marcos de significación de determinadas nociones (James, 2005), es interesante pensar cómo los niños y niñas insertos en relaciones de poder adultocéntricas igual tienen injerencia en las disputas de sentido y en la construcción de sus realidades, en tanto van aprehendiendo a la vez que modificando los significados culturales en los que están inmersos.

Estas investigaciones, así como las de la psicóloga Lucía Rabello de Castro (2002 y 2008), sostienen que el significado de todas las categorías de nuestro pensamiento son siempre históricas, están en constante devenir en términos individuales y sociales, y que los contextos son constitutivos de los procesos cognitivos en una variedad de escalas, que incluyen las relaciones con los sujetos y objetos presentes, pero también aquellas que se conectan con la historia pasada y con otros espacios, considerando las estructuras político-económicas y su puesta en juego en cada situación. Al mismo tiempo, esta perspectiva asume la complejidad de los contextos en tanto considera a los otros sujetos presentes con sus saberes y recorridos, que hacen de cada escenario
4. En psicología, este término hace referencia a las tradiciones tanto piagetiana como vigotskiana, que ponen el acento en la génesis de la producción de conocimiento, o sea, en el hecho de que este se construye y modifica en el tiempo y el espacio, en una clara diferenciación con el apriorismo y el empirismo (Castorina, 2012). 
una posibilidad múltiple, aunque nunca infinita ni azarosa. Tanto la materialidad del mundo, como las historias de los sujetos que participan de una actividad, condicionan los rumbos de los conocimientos allí producidos, sin jamás determinarlos.

Desde este marco teórico nos proponemos documentar lo específico de lo que conocen los niños y niñas del Movimiento sobre la política a partir de distintas escalas de sus propias prácticas, sin esencializarlos como grupo. Para ello utilizamos la etnografía como herramienta privilegiada para acceder a múltiples situaciones de interacción de los niños y niñas entre sí, con los sujetos adultos y con el mundo social (Rockwell, 2009) y construir conocimiento desde la descripción hacia la configuración de categorías que dan cuenta de las distintas formas de vivir la vida y de entenderla. Articulamos esta propuesta metodológica con una serie de entrevistas guiadas por el método clínicocrítico, que recupera la tradición constructivista de la psicología y, a partir de allí, nos permite una entrada a las concepciones que los sujetos tienen de sus procesos de participación en el marco de relaciones específicas que se da en un campo, lo que da lugar al estudio de "las relaciones entre la construcción de las ideas de los niños y las prácticas sociales" (García Palacios y Castorina, 2010, p. 98). Todo esto en el marco de una investigación comprometida con la organización en la que se trabaja, asumiendo las complejidades que allí surgen, así como los focos de análisis originados en los cruces entre la academia y la militancia, que entendemos fortalecen la investigación y nos obligan a concebir la ciencia como hecho social, atravesado por relaciones sociales múltiples que deben ser explicitadas (Hale, 2006; Fernández Álvarez y Carenzo, 2012; Wolanski, 2016).

\section{Todo espacio es político}

La casa del Movimiento es un edificio de tres pisos que ocupa casi media cuadra en el centro del barrio porteño de Almagro. Era una escuela pública que cerró y fue abandonada en la década de 1990, hasta el año 2001, cuando fue tomada por el movimiento, y entonces cada aula se convirtió en una habitación de familia. Las habitaciones ocupadas son más de treinta, en las que viven más de cincuenta niñxs. Cada cuarto, que suele ser pequeño para las cinco o seis personas que lo habitan, posee un baño propio, mientras que la cocina se comparte por piso y el tendedero para colgar la ropa es uno solo para toda la casa.

La planta baja tiene un salón grande vacío, que probablemente oficiaba de patio de recreo, y dos habitaciones, que se utilizan para reuniones y para la merienda diaria que el movimiento le otorga a los niños y niñas de la casa. En la parte de atrás de la planta baja hay un patio grande, que supo ser una cancha de futbol, vóley, quemado, o el juego de turno, y también albergaba las piletas que algunas familias armaban en verano y compartían entre todos los chicos y chicas. Hoy, ese lugar funciona de estacionamiento para aquellas familias que lograron comprarse un auto en los últimos años de bonanza económica. Estas pagan por ese lugar un módico alquiler, que le sirve de ingreso a la casa para sustentar algunos gastos colectivos de luz, agua y demás impuestos.

El dueño, por su parte, reclamó el derecho de usufructo del patio y lo destruyó con la intención de construir un sótano que funcionara como estacionamiento para alquilar al público en general, y así recuperar parte del valor de la propiedad que perdió con la ocupación. El proyecto nunca se concretó y el lugar quedó abandonado y lleno de escombros, con los pocos autos de las familias y la prohibición absoluta para los niños y niñas de jugar allí. Los pasillos, las escaleras, el salón central de la planta baja y el patio son compartidos por todas las familias y las discusiones por los usos de estos espacios son permanentes entre los adultos y para con los niños y niñas de la casa, aunque recién puedo ahora relacionarlo con la investigación en curso. 
La antropología política ha puesto, históricamente, el foco en la territorialidad y el espacio, pero de todas las veces que había ido y preguntado por las marchas del Movimiento, por sus reclamos, no había encontrado allí interés por parte de los chicos y chicas:

Yuri: Me gustan las marchas por los tambores

Paula: ¿Pero por qué van a las marchas?

Yuri: Por los tambores [piensa unos instantes ante mi probable cara de desconcierto].

Le puedo preguntar a mi mamá. (Entrevista a Yuri, 10 años, casa del Movimiento,

Buenos Aires, septiembre 2016)

Muchos y muchas otras no participan de esas instancias y la gran mayoría no quiere mudarse (aunque todos y todas hablan de la necesidad de arreglar el lugar y comprarle cosas); en general, los chicos y chicas no comparten con los y las adultas el deseo de tener una casa propia: "yo no me quiero ir, acá tengo a todos mis amigos" (Teo, 10), "debe ser re aburrido estar en una casa solo" (Giselle, 8), (ambas entrevistas individuales realizadas en la casa del Movimiento en octubre de 2016). Y Tamara (12), que de hecho se mudó hace dos años a una casa individual con su mamá y su hermana, suele ir a visitar la casa y quejarse de lo mucho que extraña estar allí y de las ganas que tiene de volver.

Tardé en notar que estos niños y niñas ponen en disputa la categoría de espacio dentro de la propia casa, y así transgreden los límites que les ponen los adultos desde la palabra y la acción. Los registros dan cuenta de permanentes retos hacia los chicos por el ruido y por ensuciar y romper pasillos y ventanas, mientras ellos siguen haciendo pases con la pelota y buscando a sus compañeros en las escondidas. Las entrevistas (realizadas todas individualmente entre febrero y abril de 2017 en la casa del Movimiento) muestran la queja de este grupo por el uso restrictivo que los y las adultas les habilitan hacer: "Queríamos bajar [al patio] con unas amigas y no nos dejaban porque la llave la tienen solo los que tienen auto y los del consorcio" (Florencia, 9), "cuando estamos en el pasillo nos echan" (Andrés, 8), "no nos dejaban jugar con la pelota y tampoco nos dejaban correr" (Mauricio, 11), "queríamos jugar en la casa, queríamos un espacio" (Jaime, 13), "si voy mi papá me va a mandar adentro y yo quiero salir afuera" (Giselle, 8). Yuri (10), pelota en mano, incluso se quejó de las contradicciones que los grandes presentaban sobre el tema:

La pelota es del cumpleaños de Jacob [otro niño de dos años del hospedaje], pero acá nos dicen que no juguemos a la pelota, pero nos dan pelotas de cumpleaños. La próxima vez que me digan que no puedo jugar con la pelota les voy a decir que la pelota me la dio la mamá de Pablo [tío de Jacob] y que la reten a ella. (Registro de campo, casa del Movimiento, Buenos Aires, agosto 2016)

A su vez, esta división de poder sobre el espacio también se produce dentro del grupo de chicos, en el que los más grandes, a veces, restringen la presencia de los más pequeños o se quejan de ella: "pero que no vengan los chiquitos" (Paola, 14, registro de campo, casa del Movimiento, Buenos Aires, junio 2017); "todos tienen la llave del estacionamiento menos los chiquitos, porque si no, se pierde" (Natalia, 13, casa del Movimiento, Buenos Aires, marzo 2017).

Teo (10) cuenta que la reunión a la que convocaba el cartel mostrado al inicio de este trabajo se llamó, en parte, porque

el estacionamiento antes era un patio, tenía esta parte de futbol, acá había un arco y acá otro. Y allá estaba la parte de vóley, pero el dueño quiso hacer un estacionamiento y rompió todo y después igual no hizo nada y los grandes aprovecharon y pusieron sus autos. (Entrevista, la casa del Movimiento, Buenos Aires, octubre de 2016) 
Natalia (13) agrega que "no nos dejan jugar en los pasillos, pero después queremos salir al patio y tampoco nos dejan porque están los autos. Les importan más los autos que que nosotros la pasemos bien" (registro de campo, casa del Movimiento, Buenos Aires, agosto 2016). Si bien adultos y niños comparten las condiciones de precariedad habitacional urbana y, por lo tanto, comparten "una serie de modos de habitar y representar el espacio", su experiencia con este medio "es moldeada a su vez por la condición etaria, de género" (Hernández, et al., 2012, p. 2) y está atravesada por los marcos de significado de cada sujeto. En este sentido, lo que niños y niñas conocen como el uso apropiado del espacio difiere sustancialmente de lo que los y las adultas pretenden enseñarles desde la palabra y las prácticas cotidianas.

Para los adultos, los lugares compartidos son de paso, apenas están allí unos segundos. En los registros no encontramos más que algún saludo o un chiste pasajero, o un colgar la ropa y retirarse rápidamente a la privacidad de la habitación. Lo cierto es que los espacios comunes son, muchas veces, escenarios de conflicto entre los y las adultas, motivo por el cual suelen evitarlo: "no, yo no salgo mucho, prefiero estar tranquila acá en mi casa" (Mirta, 41, registro de campo, casa del Movimiento, Buenos Aires, julio 2017). Uno de los motivos principales de estas peleas es el comportamiento de los propios chicos y chicas en los pasillos y escaleras, los gritos, los papeles que dejan siempre tirados, las cosas que rompen y las trompadas que, en algún momento de la tarde, vuelan de un lado a otro hasta que alguien sale lastimado y acusa a algún otro, lo que provoca duraderos conflictos entre los adultos, que los chicos y chicas olvidan rápidamente para volver al juego.

Los y las adultas no quieren estar juntos en la casa en esas condiciones, y por eso salen a las calles a reclamar por vivienda y trabajo digno, a ocupar el espacio público y reclamar lo que denominan una vivienda digna, en contra de las voluntades políticas del gobierno. En un tono similar, los niños y las niñas hacen uso de los lugares comunes dentro de la casa, a pesar de las voluntades adultas, de quienes, sin embargo, conocieron en primer lugar la disputa por el territorio. La noción de espacio se pone aquí en juego en las intersecciones mencionadas por Toren (2012) entre los conocimientos adultos y lo que con ellos hacen los chicos del Movimiento en sus prácticas cotidianas, y llegan a disputar sentidos y territorios concretos. Si bien los chicos y las chicas han dado cuenta de los conflictos mencionados anteriormente por los adultos dentro de la casa, ellos y ellas valoran los espacios compartidos en tanto lugares de encuentro, lo que da cuenta de que el espacio es también las relaciones que se producen allí entre las personas (Lopes y Vasconsellos, 2006).

Cada tarde de trabajo de campo encontré a los niños y niñas sentados en los pasillos conversando, compartiendo algún video en la computadora, jugando a las escondidas, a la pelota, a la guerra, a los zombies (juegos de persecución). También salen a hacer la tarea juntos, se encuentran en los pasillos con los cuadernos y las mochilas, les piden ayuda a los más grandes y a veces también a los adultos. También se pelean mucho, se insultan, incluso se golpean a veces, pero son actitudes consideradas por ellos y ellas mismas como parte del trato cotidiano; los enojos son pasajeros, el malestar dura apenas unos segundos antes de que vuelvan todos y todas a seguir jugando, conversando o estudiando.

En el marco de estas experiencias de vivienda colectiva, podríamos decir que las categorías de público y privado se tensionan, en tanto niños y adultos reorganizan sus esquemas de significado para darle lugar a lo nuevo y aún indefinido del espacio común. Las mismas autoras antes citadas describen que "El hecho de pasar buena parte del día en el espacio público caracteriza a la infancia y juventud de los sectores más pobres del BA" (Hernández et al., 2012, p. 10), lo que para este caso equivale a los lugares compartidos dentro de la casa, que los chicos y chicas entienden como propios y por ello los ocupan para jugar allí juntos. El territorio se torna disputa intergeneracional bajo 
el manto de la ambigua categoría de un lugar de todos, en tensión entre lo colectivo y común, y entre lo prohibido y conflictivo. Holloway y Valentine (2000) dicen, en su análisis sobre las geografías infantiles, que "el comportamiento indisciplinado de los otros niños (dionisíacos) puede poner en riesgo el control adulto del espacio 'público"' (p. 10). En este sentido, vemos ponerse en marcha dentro del propio Movimiento los discursos antes mencionados sobre lo que los niños y niñas están o no preparados para realizar; en este caso, si son capaces o no de cuidar el espacio mientras juegan, a lo que ellos respondieron con la pregunta de si son los adultos capaces de garantizarles un espacio de juego acorde con sus necesidades.

\section{“Una reunión de niños"}

La respuesta sobre las restricciones del espacio, creada por los niños y niñas, adquirió la forma de una reunión, que constituye la base organizativa del Movimiento para las y los adultos. Casi todas las semanas, todas las familias son llamadas a una reunión, en la que revisan las cuentas de los servicios que hay que pagar en la casa, repasan las actividades del Movimiento y resuelven los conflictos que surgen en la vivencia colectiva. Allí también se elige por consenso al consorcio, constituido por tres encargados de administrar las decisiones colectivas tomadas en cada reunión, una tarea que a nadie le entusiasma demasiado y que, por ello, rota cada tres o cuatro meses entre todos los adultos de la casa. Los niños y las niñas no participan de las reuniones, que se hacen a puertas cerradas en un cuarto con llave que solo poseen algunos miembros adultos de la casa, aquellos que cumplen temporalmente el rol de consorcio y administran las resoluciones colectivas: "Yo no fui a la reunión, no vamos los chicos, van los papás. Una vez entré igual a pedirle algo a mi mamá, pero me fui rápido" (Rosa, 8); "los más chiquitos se quedan a veces con los papás, pero nosotros no vamos" (Jeremías, 6), (ambas entrevistas individuales, casa del Movimiento, Buenos Aires, febrero 2017).

Partiendo de los registros, podemos afirmar que hay una intención de no involucrar a los chicos en los asuntos del Movimiento, en tanto no se los invita a discutir los asuntos de la casa, o a participar de las marchas asiduamente. Tampoco suelen conversar sobre los motivos de las marchas y en reiteradas ocasiones les pidieron explícitamente que "no te metas en esto, son cosas de grandes" (Dalila, 39. Registro de campo, casa del Movimiento, Buenos Aires, julio 2017). La separación generacional es también espacial, en tanto el cuarto donde se llevan adelante las reuniones está siempre bajo llave y no es habitado por los chicos y chicas. A pesar de esta separación, ellos y ellas parecen estar al tanto de lo que en las reuniones se discute: "Hablan de cosas del Movimiento" (Andrés, 8), "lo que gastan, la luz, todo eso" (Rosa, 8), (ambas entrevistas individuales, casa del Movimiento, Buenos Aires, marzo, 2017), "hablan de las pelotas y de que rompemos todas las luces" (Giselle, 8), "charlan, hablan de un montón de cosas, de lo que hay que pagar, de las otras casas [del Movimiento]" (Teo, 10), (ambas entrevistas individuales, casa del Movimiento, Buenos Aires, octubre 2016). Otra vez, un conocimiento reservado para los adultos, en este caso, sobre formas de organización, fue incorporado a la red de significados de los chicos con sus propias modificaciones, lo que nos lleva a afirmar con Rabello de Castro (2002) que si los niños solo aprendieran aquello que los adultos quieren enseñarles "la especie humana ya se habría extinguido hace mucho tiempo" (p. 52, traducción propia).

También llama la atención, en este punto organizativo de los niños y niñas, la decisión de invitar al consorcio "para que de verdad se haga" (Natalia, 13, registro de campo, casa del Movimiento, Buenos Aires, agosto 2016) y la definición del día y el horario:

Aún en ronda, cada vez con más chicos atraídos por la situación y tratando de acordar entre todos la fecha y la hora, barajan algunas opciones. Dicen que sábado, 
pero lo descartan porque la mayoría de ellos está en la escuelita [espacio de apoyo] y el domingo tampoco porque ese día se descansa y nadie va a querer bajar. Así que resuelven llamar a la reunión el viernes a las 20.30 hs, que ya todos volvieron del trabajo y al otro día no hay que levantarse temprano. Aclaran que los van a ir a buscar, porque tienen miedo de que no los tomen en serio y nadie vaya (registro de campo, casa del Movimiento, Buenos Aires, agosto 2016)

Es clara la actividad creativa de los niños y niñas en esta escena, los diálogos entre ellos antes de anotar cada frase con que el cartel mostrado con anterioridad (ver Figura 1) convoca a la reunión, la palabra "para" tachada y corregida por un "de niños", con la que asumen allí mismo su rol de organizadores, marca ese camino. Pero queremos resaltar también el marco de conocimientos y prácticas adultas en el que ellos se mueven, que restringe, en tanto limita y posibilita las construcciones de sentido posibles de estos sujetos (García Palacios, 2012). Lo mismo podemos decir de las definiciones sobre la difusión de la convocatoria, dado que apenas Natalia (13) terminó de escribir, se levantaron Florencia (9) y Ema (9) al grito de “ $¡$ Vamos a buscar cinta!", y cuando volvieron, ninguno dudó en pegar el cartel en el pasillo del primer piso, "porque es donde todo el mundo baja y lo ve" (Ema, 9), "ahí se pegan las cosas que querés que todos sepan" (Andrés, 8), "siempre miran las noticias que hay en ese pasillo" (Jaime, 13), (registros de campo, casa del Movimiento, Buenos Aires, agosto 2016).

En cuanto a la firma del cartel, "los chicos del Movimiento", resulta llamativa como identidad colectiva autoadjudicada, en tanto los niños y niñas se habían mostrado renuentes o dubitativos acerca de su pertenencia al Movimiento. En una entrevista individual, Florencia (9) dijo "yo no soy del Movimiento, los grandes son"; y Giselle (8), por su parte, dijo "vivimos en el Movimiento, pero no sé qué es" (registros de campo, casa del Movimiento, Buenos Aires, marzo 2017 y octubre 2016, respectivamente). Sin embargo, a la hora de cerrar el cartel, Natalia (13) propuso enseguida esa autodenominación, que no pude rastrear en ninguno de los registros previos ni en los posteriores, por lo que se presenta como una creación original del momento, surgida a partir de un conflicto preciso, que los y las ubicó como un mismo grupo y con una pertenencia clara a la organización. Antes, Pablo (8) había propuesto firmar solo como "los chicos", pero a ninguno de los presentes le resultó demasiado convincente, mientras que se entusiasmaron con la propuesta de Natalia (13).

La promesa "los pasaremos a buscar" habla, en primer lugar, de una cierta desconfianza por parte de los chicos y las chicas respecto de que los adultos realmente concurrieran a la reunión. Este sentimiento estuvo presente a lo largo de todo el proceso de armado del cartel, en el que se escucharon frases como "para mí, no van a venir" y "ni van a mirarlo [al cartel]". Si bien no queda claro en los registros hasta qué punto esta práctica de ir a buscar es algo que realizan los adultos, sí podemos dar cuenta de que son muchas las reuniones a las que los más grandes no van por trabajo, cansancio o desinterés y, frente a esta posibilidad, conocida por los y las chicas, configuraron una estrategia de persuasión que, de hecho, funcionó.

Por otro lado, los conceptos de "huelga" y "derechos" no parecen ser traídos de las prácticas del Movimiento, en tanto no suelen escucharse dentro de la casa, ni en las marchas, ni están escritos en los carteles de la organización. En cambio, remiten a otros universos conceptuales a los que niños y niñas recurrieron para hacerse oír. Al hacer trabajo de campo en la escuela a la que asisten muchos de ellos y ellas, pude observar una variada gama de carteles pegados en las paredes en los que se utiliza la palabra "derechos" asociada a las infancias. Además, la mamá de uno de los chicos me comentó, mientras se reía, en otra situación y por otro tema, que "ahora que en la escuela están 
con eso de los derechos [los chicos] vienen con cualquier cosa" (registro de campo, Buenos Aires, agosto 2017).

Durante los días en que se desarrolló el conflicto por el espacio, los chicos y las chicas repitieron varias veces que tenían derecho a jugar y que por eso les correspondía un lugar, lo cual parecía brindarles confianza en su reclamo, cierta legitimidad por los derechos que ellos conocían y que estaban haciendo valer en un campo ajeno a la temática particular, pero muy familiarizado con la lucha colectiva por aquello que se considera justo. ${ }^{5}$ La noción de "huelga", en cambio, no volvió a mencionarse, y fue siempre remplazada por la exigencia de tener "una reunión de niños" con el consorcio, como significación local de esa idea de reclamo colectivo.

\section{La política entre grandes y chicxs}

En cuanto a la respuesta de los adultos, los primeros en ver el cartel sonrieron con complicidad, "así que ahora van a pelear también los niños, muy bien" (Mirta, 41, registro de campo, casa del Movimiento, Buenos Aires, agosto 2016) y otra señora que pasó por el pasillo volvió especialmente a sacarle una foto mientras sonreía. Sin embargo, en los siguientes días se produjo un malestar en la casa, dado que algunos adultos cuestionaron el reclamo, alegando que no habían sido los chicos los creadores de la propuesta: "algunos grandes se enojaron, dijeron que estábamos locos" (Ema, 9); "nos preguntaban de dónde lo sacamos" (Natalia, 13), (ambas entrevistas individuales, casa del Movimiento, Buenos Aires, marzo 2017). Incluso unos días antes de la reunión, una de las mamás llamó a mi teléfono para preguntarme si yo había estado involucrada, porque no les había gustado nada que los chicos hicieran eso.

Podemos pensar, entonces, que la propia categoría de infancia se puso en juego en el Movimiento, en tanto algunos de los adultos asumieron con orgullo este saber de los niños y niñas y otros aseguraron que estos no eran capaces de organizarse solos o que, en caso de haberlo hecho, eso no correspondía a aquello que se espera de los y las pequeñas. En este sentido, recuperamos el estudio de Wolanski (2013) sobre "los modos en que las categorías etarias se construyen socialmente en las luchas en cada uno de los campos sociales" (p. 5) para pensar de qué modo se viven estas tensiones dentro de familias militantes que comparten vivienda, crianza y pobreza.

Estas familias comparten, además, una institucionalidad organizativa, que llevó el caso de los niños y niñas organizadas a tener relevancia regional dentro del Movimiento. Uno de los dirigentes nacionales del Movimiento, en una reunión general de todas las casas de ciudad dijo en un momento: "Allá se organizaron los chicos para pelear por lo justo, miren qué ejemplo", mientras otra de las referentes negaba con la cabeza y decía por lo bajo "no, no, no, eso está mal". Entendemos que aquí se pone en juego lo que Holloway y Valentine (2000) denominan "conocimientos peligrosos", como aquello que los adultos no comparten con los más pequeños porque, justamente, produce un "peligro" sobre los propios chicos (refugiados en las necesidades de cuidado), o sobre los privilegios adultos en determinados espacios. Con más o menos acuerdo adulto, los acontecimientos sucedidos a partir del pedido de reunión de los chicos, y luego las palabras del dirigente, ubicaron en el centro de la escena una forma de hacer política entre las generaciones que forja el contexto de prácticas sociales en el que niños y niñas construyen su conocimiento (García Palacios, Shabel, Horn y Castorina, 2018).

Cuando efectivamente se llevó adelante la reunión de niños, Natalia (13) explicó de dónde había surgido la idea:
5. Asumimos la necesidad de problematizar, en futuras investigaciones, las formas en las que el Estado se hace presente en estas negociaciones de conocimiento, como sucede aquí por medio de la escuela. 
hace mucho que lo queríamos hacer, yo con algunas chicas, pero no nos animábamos, teníamos miedo de que nos reten. Al final, la idea la sacamos hablando con una señora del consorcio, que le preguntamos por qué ellos se podían quejar de las cosas y nosotros no, y ella nos dijo, bueno, háganlo ustedes también, y lo hicimos (registro de campo, casa el Movimiento, Buenos Aires, octubre 2017).

Las mujeres presentes en la conversación, todas del consorcio, parecieron aceptar la respuesta con agrado y avanzaron sobre los reclamos de los chicos, que se discutieron durante aproximadamente una hora. Allí, las adultas se comprometieron a arreglar un espacio de juego para niños y niñas en la casa y estos aceptaron respetar sus horarios de uso y dejar de jugar en los pasillos. Firmaron un acta todos los presentes y las autoridades regionales del Movimiento fueron notificadas de los acontecimientos y acuerdos finales. Creemos pertinente afirmar que los conocimientos puestos en juego en esta escena de organización de una reunión de niños nos permiten reconstruir la dialéctica epistémica que se produce entre los sujetos, los objetos y los contextos a diversas escalas de la práctica, tanto en el caso de los niños y niñas, como en el de los y las adultas. El espacio, la organización y la disputa como experiencias cotidianas de lo político nos acercan a la idea de que "hacer juntos(as) requiere un trabajo pedagógico que porta con él una dinámica ejemplar no exenta de relaciones de poder" (Fernández Álvarez, 2015, p. 18) que se juegan, en este caso, intergeneracionalmente.

\section{Comentarios finales}

Los acontecimientos aquí analizados se sucedieron en dos intensas semanas del invierno de 2016, después de las cuales me resultó urgente repensar qué es lo que estaba buscando al indagar en las construcciones de conocimiento de estos niños y niñas en el campo de la política. El realismo crítico en el que se basan las investigaciones de Toren (2012) y García Palacios (2012) nos guía en la delimitación de este objeto que, en permanente diálogo con los sujetos que lo construyen cotidianamente, existe y puede ser analizado en sus relaciones de poder, en las jerarquías y cómo ellas se disputan en el control del espacio y los saberes. Acordamos en este punto con Fernández Álvarez cuando afirma que llevamos adelante estos estudios en pos de "trascender el interés por las prácticas y las relaciones para iluminar la sustancia de la política, es decir, el contenido de aquello que se produce, crea y hace a partir de esas prácticas y relaciones" (Fernández Álvarez, 2015, p. 28).

En este sentido, sin que exista una categoría de lo político separado de las demás esferas de su vida, estos niños y niñas han forjado una serie de conocimientos sobre las relaciones de poder y la organización colectiva, que les permiten pugnar en este campo cuando lo consideran necesario. En el creativo proceso de organizar su reunión, los niños y las niñas pusieron en juego dichos conocimientos, y produjeron, a su vez, una nueva práctica de acción colectiva, a partir de la cual disputaron los sentidos y usos del espacio en el Movimiento, y las formas en las que se desarrollan las relaciones intergeneracionales.

Al mismo tiempo, esta investigación propone una reflexión sobre la propia categoría de infancia a partir de la pregunta por lo que ella puede o no conocer en relación con sus momentos de maduración biológica, con aquello que les resulta socialmente significativo a los niños y las niñas; aquello que los adultos quieren o no que conozcan y crean que pueden o no comprender. En línea con otros trabajos ya citados que abordan esta pregunta, nuestro enfoque etnográfico abre este interrogante en el contexto específico de niñeces que viven y conocen en organizaciones sociales territoriales con prácticas cotidianas de ocupación del espacio (público y privado) y de lucha colectiva. 


\section{Agradecimientos}

Agradezco al Consejo Nacional de Investigaciones Científicas y Técnicas (CONICET) por el financiamiento de esta investigación.

\section{Financiamiento}

Consejo Nacional de Investigaciones Científicas y Técnicas (CONICET).

\section{Sobre la autora}

Paula Shabel es Doctora en Ciencias Antropológicas (UBA). Becaria Postdoctoral del CONICET, Docente ayudante de la materia Psicología y Epistemología Genética (Cát. Barreiro), Facultad de Psicología (UBA). 


\section{Q Referencias bibliográficas}

》 Bonnet, A. (2008). La hegemonía menemista. El neoconservadurismo en Argentina, 19892001. Buenos Aires: Prometeo.

"Cañedo Rodríguez, M. y Espinosa, A. M. (2011). Antropología política: temas contemporáneos. Barcelona: Bellaterra.

" Castorina, J. A. (2012). Psicología y epistemología genéticas. Buenos Aires: Lugar.

"Carli, S. (coord.) (2009). La cuestión de la infancia. Entre la escuela, la calle y el shopping. Buenos Aires: Paidós.

"Carli, S. (2012). Niñez, pedagogía y política. Transformaciones de los discursos acerca de la infancia en la historia de la educación argentina entre 1880 y 1955. Buenos Aires: Miño y Dávila.

"Fernández Álvarez, M. I. (2015). Hacer juntos(as). Dinámicas, contornos y relieves de la política colectiva. Buenos Aires: Biblos.

"Fernández Álvarez, M. I. y Carenzo, S. (2012). "Ellos son los compañeros de CONICET”: El vínculo con organizaciones sociales como desafío etnográfico. PUBLICAR-En Antropología y Ciencias Sociales, 12, 9-33. Recuperado de http://ppct.caicyt.gov.ar/index.php/ publicar/article/view/1562/3003

" García Palacios, M. (2012). Religión y etnicidad en las experiencias formativas de un barrio toba de Buenos Aires (tesis de Doctorado con mención en Ciencias Antropológicas). Facultad de Filosofía y Letras, Universidad de Buenos Aires, Buenos Aires, Argentina.

"García Palacios, M. y Castorina, J. A. (2010). Contribuciones de la etnografía y el método clínico-crítico para el estudio de los conocimientos sociales de los niños. En J. A. Castorina (Coord.), Desarrollo del Conocimiento Social (pp. 83-112). Buenos Aires: Miño y Dávila.

» García Palacios, M., Shabel, P., Horn, A., Castorina, J. A. (2018). The Interpretation of Context in Studies on Children's Knowledge: An Examination of the Uses and Meanings of "Context" in Anthropology and Constructivist Psychology. Integrative Psychology and Behavioral Science, 52(1). En prensa.

»Gentile, M. F. (2011). Niños, ciudadanos y compañeritos: un recorrido por los distintos criterios para el trabajo de inclusión social de niños y adolescentes de sectores vulnerables. En I. Cosse, V. Llobet, C. Villalta y M. Zapiola (Comps.), Infancias: políticas y saberes en Argentina y Brasil (siglos XIX y XX) (pp. 265-286). Buenos Aires: Teseo.

" Gentile, M. F. (2015). La niñez en los márgenes, los márgenes de la niñez. Experiencias callejeras, clasificaciones etarias e instituciones de inclusión en niños/as y jóvenes del AMBA (tesis de doctorado con mención en Ciencias Sociales). Facultad de Ciencias Sociales, Universidad de Buenos Aires, Buenos Aires, Argentina.

" Girola, M. A. y Thomasz, A. G. (2013). Del "derecho a la vivienda" al "derecho a la cultura": reflexiones sobre la constitución del "derecho a la ciudad" en Buenos Aires desde una perspectiva etnográfica. Anuário Antropológico [Online], II, 131-163. Recuperado de https://journals.openedition.org/aa/593

»Grimberg, M. (2009). Poder, políticas y vida cotidiana. Un estudio antropológico sobre protesta y resistencia social en el área metropolitana de Buenos Aires. Revista de Sociología Política, 17(32), 83-94. Recuperado de http://www.scielo.br/pdf/rsocp/v17n32/ v17n32ao6.pdf 
» Hale, C. (2006). Activist research vs. Cultural Critique: Indigenous Land Rights and the Contradictions of Politically Engaged Anthropology. Cultural Anthropology, 21(1), 96-120.

» Hernández, M. C., Chaves, M. y Cingolani, J. (2012). Construcción y disputa de alteridades etarias en contexto sociourbano de pobreza en La Plata [Argentina]. En VII Jornadas de Sociología de la UNLP. Argentina en el escenario latinoamericano actual: Debates desde las ciencias sociales. La Plata: Universidad Nacional de La Plata. Facultad de Humanidades y Ciencias de la Educación. Departamento de Sociología. Recuperado de https:// www.aacademica.org/ooo-097/258.pdf

» Holloway, S. L. y Valentine, G. (Eds.) (2000). Children's geographies: Playing, living, learning. Londres y Nueva York: Routledge.

» James, A. (2005). Life Times: Children's Perspectives on Age, Agency and Memory across the Life Course. En J. Qvortrup (ed.), Studies in Modern Childhood. Society, Agency, Culture (pp. 189-2001). Nueva York: Palgrave MacMillan.

»Liebel, M. (2016). ¿Niños sin niñez? Contra la conquista poscolonial de las infancias del Sur global. Millcayac-Revista Digital de Ciencias Sociales, 3(5), 245-272. Recuperado de http://revistas.uncu.edu.ar/ojs/index.php/millca-digital/article/view/77o/o

» Lopes, J. J. M. y Vasconsellos, T. D. (2006). Geografia da infância: territorialidades infantis. Currículo sem fronteiras, 6(1), 103-127. Recuperado de http://www.curriculosemfronteiras.org/vol6iss1articles/lop_vasc.pdf

» Manzano, V., Fernández Álvarez, M. I., Triguboff, M. y Gregoric, J. (2008). Apuntes para la construcción de un enfoque antropológico sobre la protesta y los procesos de resistencia social en la Argentina. En M. Grimberg, M. J. Fernández y M. I. Fernández Álvarez (Comps.), Investigaciones en Antropología Social. Buenos Aires: Facultad de Filosofía y Letras y Antropofagia. Recuperado de http://theomai.unq.edu.ar/conflictos_sociales/ Enfoq\%20Antropo\%2oProtest\%20y\%2oRsisSocial\%20(Manzano-Grimberg-FernaAlvarez).pdf

»Padawer, A., Scarfó, G., Rubinstein, M. y Visintín, M. (2008). Movimientos sociales y educación: debates sobre la transicionalidad de la infancia y de la juventud en distintos contextos de socialización. Intersecciones en Antropología, 10(1), 141-153. Recuperado de http://www.scielo.org.ar/pdf/iant/v1on1/v1on1a1o.pdf

» Pires, F. (2007). Ser adulta e pesquisar crianças: explorando possibilidades metodológicas na pesquisa antropológica. Revista de Antropología de San Pablo, 50(1), 225-270.

"Qvortrup, J. (2010). A infância enquanto categoria estrutural. Educação e Pesquisa, 36(2), 56-74. Recuperado de http://www.scielo.br/pdf/ep/v36n2/a14v36n2.pdf

» Rabello de Castro, L. (2002). A infância e seus destinos no contemporâneo. Psicologia em Revista, 8(11), 47-58. Recuperado de http://periodicos.pucminas.br/index.php/psicologiaemrevista/article/view/134/127

» Rabello de Castro, L. (2008). A politização (necessária) do campo da infância e da adolescência. Psicología Política, 14(7), 1-19. Recuperado de http://www.fafich.ufmg.br/rpp/ seer/ojs/viewarticle.php?id=32\&layout=html

» Rockwell, E. (2009). La experiencia etnográfica. Buenos Aires: Paidós.

»Santillán, L. (2009). La crianza y la educación infantil como cuestión social, política y cotidiana: una etnografía en barrios populares del gran Buenos Aires. Anthropologica, 27(27), 47-74. Recuperado de http://www.scielo.org.pe/pdf/anthro/v27n27/ao4v27n27.pdf

»Santillán, L. (2012). Quiénes educan a los chicos. Infancia, trayectorias educativas y desigualdad. Buenos Aires: Biblos. 
»Scarfó, G. (2010). Tensiones en torno a la relación entre niños, jóvenes adolescentes y trabajo. Un estudio antropológico en el seno de dos movimientos sociales. Revista Margen, 57(1), 1-11. Recuperado de https://www.margen.org/suscri/margen57/scarfo57.pdf

» Shabel, P. (2017) “Atrás de cada pibe de la calle hay un padre desocupado”. Organizaciones sociales y sindicales en lucha por la infancia digna (1983-2001). Anuario del Instituto de Historia Argentina, 17(2), e056. doi: 10.24215/2314257Xeo56

» Szulc, A. (2006). Antropología y niñez: de la omisión a las culturas infantiles. En G. Wilde y P. Schamber (Comps.), Culturas, comunidades y procesos urbanos contemporáneos (pp. 94-126). Buenos Aires: SB.

"Szulc, A. y Enriz, N. (2016). La política, las calles y la niñez indígena en Argentina. Cuadernos de campo, 8(2), 200-221. Recuperado de http://www.revistas.usp.br/cadernosdecampo/article/view/112255

» Toren, C. (2012). Antropologia e Psicologia. Revista Brasileira de Ciencias Sociais, 27(80), 21-36.

» Villalta, C. (2013). Un campo de investigación. Las técnicas de gestión y los dispositivos jurídico-burocráticos destinados a la infancia pobre en la Argentina. Civitas, 13(2), 245268. Recuperado de http://revistaseletronicas.pucrs.br/ojs/index.php/civitas/article/ viewFile/15482/10827

»Wolanski, S. (2013). “Jóvenes innovadores” y “viejos ex ENTel”. La relación entre edad y política en un ámbito laboral. En R. Borobia, L. Kropff y P. Núñez (Comps.), Juventud y política: más allá de la sorpresa. Sensibilidades y formas políticas contemporáneas (pp. 123139). Buenos Aires: NOVEDUC.

» Wolanski, S. (2016). Organizar la juventud. Un estudio etnográfico comparativo sobre experiencias juveniles de organización gremial. En F. Ferrer (Coord.), Jóvenes en Movimientos. Experiencias y sentidos de las movilizaciones en la América Latina contemporánea (pp. 267-312). Buenos Aires: CLACSO. Recuperado de http://biblioteca.clacso.edu.ar/ gsdl/collect/clacso/index/assoc/D9713.dir/informefinal-WolanskiSandra.pdf 